\title{
Residues and Distributions of Organochlorine Pesticides in China's Weihe River
}

\author{
Di Wang, Shengke Yang*, Geng Wang, Lunchuan Gao, Yanni Wang, \\ Qianli Jiang, Yuyun Chen
}

Key Laboratory of Subsurface Hydrology and Ecological Effect in Arid Region of Ministry of Education, Chang' an University, Xi'an 710054, P. R. China

Received: 28 October 2015

Accepted: 16 February 2016

\begin{abstract}
To examine the residues and distributions of hexachlorocyclohexanes (HCHs), dichlorodiphenyltrichloroethane (DDT), and other organochlorine pesticides (OCPs) in the Weihe River basin of northwest China, a gas chromatography-mass spectrometer (GC-MS) was employed to analyze the samples collected from surface water, suspended solids, and sediments. Results showed that total concentrations of HCHs, DDT, and other OCPs in surface water were in the range of 2.41-178.18, 0.94-116.83, and 3.64-37.17 ng/L, respectively; in suspended solids they were 51.76-241.23, 2.8212.23 , and $11.35-37.67 \mathrm{ng} / \mathrm{L}$, respectively; and in sediments they were $74.13-517.49,1.20-370.98$, and $7.94-110.13 \mathrm{ng} / \mathrm{g}$ dry weight, respectively. The $\alpha-\mathrm{HCH} / \gamma-\mathrm{HCH}$ ratio indicated that historical usage of technical mixtures of HCHs was the main source of HCHs. The DDT ratio indicated that DDT at most sites came from older uses of technical DDT. Compared with some guideline values of OCPs in surface water, the concentrations of HCHs and DDT were at safe levels. Meanwhile, the Weihe River sediments have high ecological risk pesticides.
\end{abstract}

Keywords: organochlorine pesticides, water, suspended solids, sediments, Weihe River

\section{Introduction}

Organochlorine pesticides (OCPs) in the environment are not only recognized as priority pollutants, but also typical of persistent pollutants (POPs). OCPs such as hexachlorocyclohexanes $(\mathrm{HCHs})$ and dichlorodiphenyltrichloroethane (DDT) have caused global attention due to their environmental persistence, high toxicity, bioaccumulation, and biomagnification in the environment $[1,2]$. China has been one of the countries with high production and consumption of $\mathrm{HCHs}$ and DDT [3]. Large amounts of OCPs were used in past

*e-mail: ysk110@126.com decades to obtain high yield to sustain overpopulation in China. HCHs and DDT were the most widely used pesticides in China during the 1950s to 1980s due to their low cost and high insecticidal efficacy. The productions of HCHs and DDT in China were 4.9 and 0.4 million tons, respectively, accounting for 33 percent and 20 percent of total worldwide production [1]. Even after the ban of technical HCH and DDT in 1983, approximately 11,400 tons of lindane (almost $\gamma-\mathrm{HCH}$ ) reportedly were still being produced [4]. And DDT has been continuously produced for about 20 years because of exports to other countries for control of malaria and production of dicofol [5]. OCPs are hard to be degraded, and they can still be detected in various environmental media such as soil, water, suspended solids, sediments, atmosphere, and organisms. 
In the water environment, trace amounts of OCPs even cause adverse biological effects on ecosystems, and the contamination can even be hazardous to humans through aquatic food [6]. Therefore, investigating the residues and distributions of OCPs in water is important because of its environmental significance.

Dated sediments are natural archives that can be used to provide comprehensive estimations of historical OCP records and reconstruct their chronology in aquatic environments [7]. Information regarding the historical accumulation processes of OCPs in lake sediments is of importance for understanding how OCPs in river systems threaten the environment and human health. Several studies have investigated the historical records of OCPs in sediment cores from marine and estuary environments $[8,9]$; however, limited data are available regarding the sedimentary records of OCPs in inland aquatic ecosystems - particularly in water, suspended solids, and sediments from rivers in arid and semiarid regions. Studies about OCP contamination in rivers in China [10-13] show that almost all of these rivers are located in humid and semi-humid regions rather than in arid and semiarid regions. However, as a typical river, the Weihe belongs to an arid and semiarid region in northwest China and is the biggest tributary of the Yellow River. In addition, it is also a source of drinking water and industrial water with a lot of human activities along the river. Reservoir construction downstream causes deposition of sediments, and the river's velocity becomes slow, which accelerates sediment deposition.

The aims of this research are to survey the residual levels and pollution status, discussing the distributions of OCPs in water, suspended solids, and river sediments. In addition, we compare the temporal trend of the pollution of OCPs with previous measurements to assess ecological risks in the basin. Furthermore, we discuss the contamination profiles and possible sources of HCHs and DDT for the purpose of future strategic environmental management.

\section{Material and Methods}

Instruments and Reagents

A gas chromatography-mass spectrometer (USA Agilent GC-MS, 7890A-5975C) and OCPs mixed solution with 18 components (including $\alpha-, \beta-, \gamma-, \delta-\mathrm{HCH}$, p,p'-DDT, o,p'-DDT, p,p'-DDE，o,p'-DDE，p,p'-DDD, $\mathrm{o}, \mathrm{p}^{\prime}$-DDD, tecnazene, hexachlorobenzene, heptachlor, aldrin, heptachlor epoxide (isomer A), heptachlor epoxide (isomer B), tetrachlorvinphos, and endrin, with each component concentration $10 \mu \mathrm{g} / \mathrm{mL}$ ) were purchased from Sigma Company (USA). All solvents used for sample pretreatment and analysis (hexane, dichlromethane, methanol, and acetone) were purchased from Oceanpak (Sweden). A Florisil SPE cartridge was purchased from CNM Technology (Germany). Anhydrous sodium sulfate is the analytical reagent. Neutral silica gel (60-100 mesh) was kept in a sealed desiccator before use.

\section{Sample Collection}

Fig. 1 shows the sampling sites in the study. We selected 37 sampling sites along the Weihe and its tributaries in order to cover the whole aquatic system in this area. The sediment samples (0-5 cm deep) were collected with a stainless steel static gravity corer. The top $1 \mathrm{~cm}$ surface layer was carefully removed with a stainless steel spoon and stored in aluminium containers. At the same time, water samples were collected at the sediment sampling sites using a cleaned brown glass bottle. The suspended solid samples were obtained by filtering the water samples using a peristaltic pump and a glass fiber membrane with a diameter of $47 \mathrm{~mm}$. All the equipment used for sample collection, transportation, and preparation were free from organochlorine contamination. The basic test indexes include COD (7.14-1056.35 mg/L), TDS (154-1370 mg/L), and $\mathrm{pH}$ (7.46-9.96).

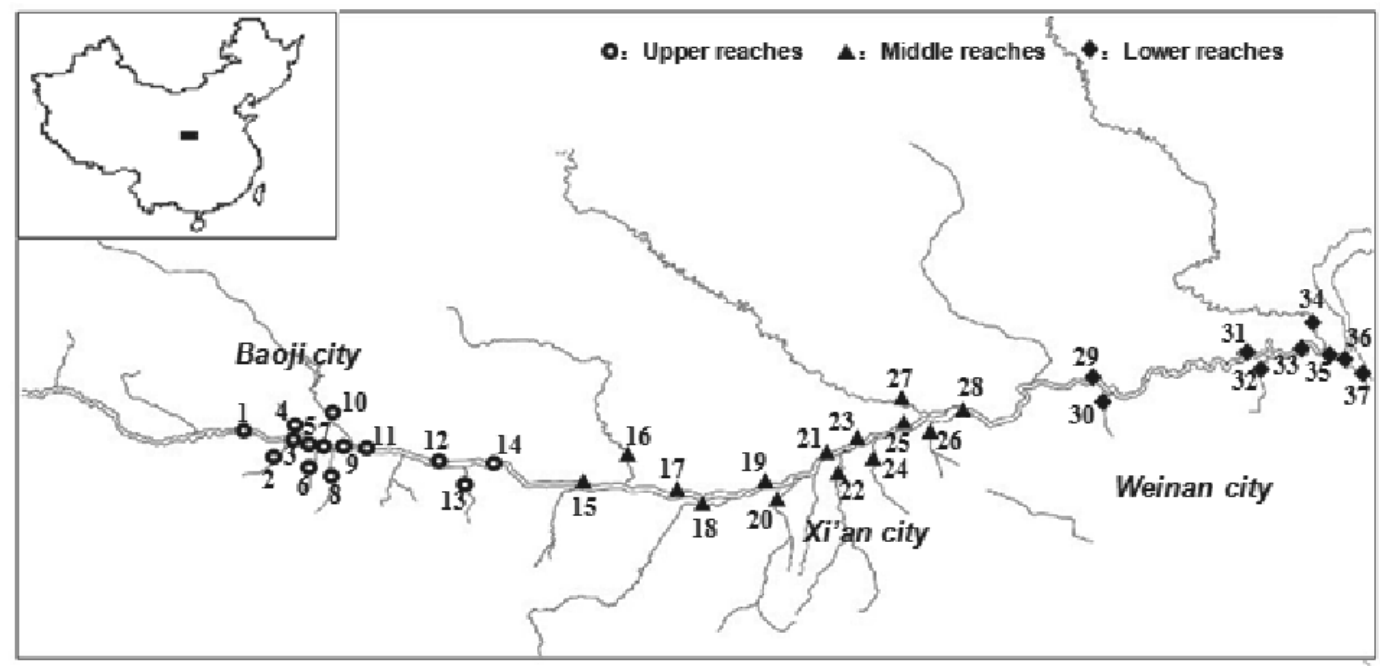

Fig. 1 Map of Weihe River and sampling sites. 


\section{Sample Pretreatment}

Water samples $(1.0 \mathrm{~L})$ were passed through the glass fiber membrane $(47 \mathrm{~mm})$ at a flow rate of $5 \mathrm{~mL} / \mathrm{min}$ using a vacuum. All water samples were extracted and purified using a solid phase extraction (SPE) system. The Florisil SPE cartridges were first conditioned with $5 \mathrm{~mL}$ of hexane, then $5 \mathrm{~mL}$ of methanol followed by $5 \mathrm{~mL}$ of ultrapure water. Following extraction, the cartridges were eluted with $10 \mathrm{~mL}$ of ethylacetate. Then the extracts were dehydrated with anhydrous $\mathrm{Na}_{2} \mathrm{SO}_{4}$ and concentrated to $1 \mathrm{~mL}$ by rotary evaporator prior to GC-MS analysis.

All sediment samples were freeze-dried, homogenized, and passed through a $150-\mu \mathrm{m}$ sieve. Hexane-acetone $(1: 2, \mathrm{v} / \mathrm{v})$ was added into each sample $(2 \mathrm{~g})$ and then the samples were extracted by ultrasonic extraction for $10 \mathrm{~min}$ before eluting by $10 \mathrm{~mL}$ hexane-dichloromethane (1:1, $\mathrm{v} / \mathrm{v})$. The extracts were concentrated to $1 \mathrm{~mL}$ by rotary evaporator prior to GC-MS analysis.

The suspended solids samples were air-dried for $48 \mathrm{~h}$, and then eluted with acetone-hexane $(1: 1, \mathrm{v} / \mathrm{v})$. The extracts were subjected to a silica gel column to remove impurities and isolates. The purification methods were the same as the methods for sediment samples indicated above.

\section{Sample Analysis}

\section{Chromatographic Condition}

Calibration column was HP-5 $(30 \mathrm{~m} \times 320 \mu \mathrm{m}$ $\times 0.25 \mu \mathrm{m})$. High-purity nitrogen served as carrier gas with flow rate of $1 \mathrm{~mL} / \mathrm{min}$ in column. The sample injection volume was $1 \mu \mathrm{L}$, and flow rate was $50 \mathrm{~mL} / \mathrm{min}$. Temperatures at the sample inlet and around the detector were $250^{\circ} \mathrm{C}$ and $300^{\circ} \mathrm{C}$, respectively.

A temperature rise program was used for the calibration column. As a result, the temperature in the column was maintained at $80^{\circ} \mathrm{C}$ for $1 \mathrm{~min}$. After that, the temperature was increased again to $200^{\circ} \mathrm{C}$ with an increasing rate of $18^{\circ} \mathrm{C} / \mathrm{min}$. Then the temperature was raised to $240^{\circ} \mathrm{C}$ with an increasing rate of $1.5^{\circ} \mathrm{C} / \mathrm{min}$, followed by the process of temperature increased to $300^{\circ} \mathrm{C}$ with an increasing rate of $20^{\circ} \mathrm{C} / \mathrm{min}$ for $3 \mathrm{~min}$.

\section{Quality Control Procedures}

All analytical operations were conducted under strict quality control guidelines. Procedural blank and spiked samples consisting of all reagents was run to check interference and cross-contamination. Surface water, suspended solids, and sediment samples were determined with good precision and recoveries.

The limits of detection for OCPs were determined as analyte concentrations in a sample that gives rise to a peak with a signal-to-noise ratio $(\mathrm{S} / \mathrm{N})$ of 3 , while the limits of quantification were determined with an $\mathrm{S} / \mathrm{N}$ of 10:1. All results were lower than the limits of quantification, while those were lower than the limits of detection. The method detection limits (MDLs) for OCPs in sediments were in the range $0.01-0.03 \mathrm{ng} / \mathrm{g}(\mathrm{dw})$. The spiked recoveries of OCPs in sediments ranged from $70.26 \%$ to $118.12 \%$. The MDLs for OCPs in surface water and suspended solids were in the range $0.02-0.06 \mathrm{ng} / \mathrm{L}$. The spiked recoveries of OCPs in surface water and suspended solids ranged from $76.11 \%$ to $108.32 \%$.

\section{Results and Discussion}

\section{Concentrations of OCPs in Surface Water}

Eighteen kinds of OCPs $\left(\alpha-, \beta-, \gamma-, \delta-\mathrm{HCH}, \quad \mathrm{p}, \mathrm{p}^{\prime}-\right.$ DDT, o, p'-DDT, p, p'-DDE，o,p'-DDE, p,p'-DDD，o,p'DDD, tecnazene, hexachlorobenzene, heptachlor, aldrin, heptachlor epoxide (isomer A), heptachlor epoxide (isomer B), tetrachlorvinphos, and endrin) were detected in the samples from all 37 sampling sites. The residual concentrations in surface water are summarized in Table 1. The total concentrations of OCPs in water were $9.35-194.93 \mathrm{ng} / \mathrm{L}$, with a mean value of $43.45 \mathrm{ng} / \mathrm{L}$.

As OCPs, HCHs and DDT were widely used in China. Residues of total HCHs (including $\alpha-, \beta-, \gamma-$, and $\delta-\mathrm{HCH}$ ) and DDT (including p, p'-DDT, o, $p^{\prime}-\mathrm{DDT}, \mathrm{p}, \mathrm{p}^{\prime}$-DDE, o, $\mathrm{p}^{\prime}-$ DDE, $\mathrm{p}, \mathrm{p}^{\prime}-\mathrm{DDD}$, and $\left.\mathrm{o}, \mathrm{p}^{\prime}-\mathrm{DDD}\right)$ in water varied from 2.41 to $178.18 \mathrm{ng} / \mathrm{L}$ (mean value of $19.85 \mathrm{ng} / \mathrm{L}$ ), and 0.94 to $116.83 \mathrm{ng} / \mathrm{L}$ (mean value of $7.37 \mathrm{ng} / \mathrm{L}$ ), respectively. The results showed that the content of HCHs in surface water was higher than that of DDT. This may be because the HCHs can go into the water more easily than DDTs. Among $\mathrm{HCHs}, \delta-\mathrm{HCH}$ isomer was far more than $\alpha-, \beta-$, and $\gamma-\mathrm{HCH}$. The order of the mean concentrations of the $\mathrm{HCH}$ isomers from high to low was: $\delta-\mathrm{HCH}(14.32 \mathrm{ng} / \mathrm{L})$ $>\gamma-\mathrm{HCH}(3.85 \mathrm{ng} / \mathrm{L})>\beta-\mathrm{HCH}(4.50 \mathrm{ng} / \mathrm{L})>\alpha-\mathrm{HCH}$ $(1.10 \mathrm{ng} / \mathrm{L})$.

DDD (p,p'-DDD, o, '-DDD) occupied $73 \%$ of total DDTs in water. The highest concentration of DDTs in water was found at the upper reaches of the Weihe (Fig. 2 ), which is surrounded by many villages.

Compared with other regions around the world, the levels of $\mathrm{HCH}$ in Weihe surface water from were lower than those in the Qiantang River, China [14] and Küçük Menderes River, Turkey [15], but were higher than those in the Chenab River in Pakistan [16], the Yangtze in China [17], and the Nestos in Greece [18] (Table 2 [14-18]). The DDT content in water from the Weihe was similar to that in the Küçük Menderes [15]. HCHs and DDT were sourced from past heavy application, as well as recent new input such as lindane and dicofol. Some kinds of OCPs (including aldrin, endrin, heptachlorm, and heptachlor epoxide), which had never been used in large amounts in northwest China, could also be detected in most Weihe samples (Fig. 2).

According to the Chinese official surface water guidelines (GB3838-2002) [19], the concentrations of HCHs and DDT in a drinking water source should be below 5,000 and 1,000 ng/L, respectively. The present study showed that the concentrations of $\mathrm{HCHs}$ 
Table. 1. OCPs in water and suspended solids and sediments from the Weihe River.

\begin{tabular}{|c|c|c|c|c|c|c|}
\hline \multirow{2}{*}{ OCP compounds } & \multicolumn{2}{|c|}{ Water (ng/L) } & \multicolumn{2}{|c|}{ Suspended solids (ng/L) } & \multicolumn{2}{|c|}{ Sediment (ng/g dw) } \\
\hline & Range & Mean & Range & Mean & Range & Mean \\
\hline tecnazene & $0.07-3.59$ & 0.47 & $0.18-8.02$ & 1.42 & $0.06-3.53$ & 0.81 \\
\hline$\alpha-\mathrm{HCH}$ & $0.04-2.87$ & 1.10 & $1.16-43.09$ & 11.85 & $0.96-131.64$ & 26.25 \\
\hline hexachlorobenzene & $0.11-7.67$ & 1.16 & $1.47-8.42$ & 4.00 & $0.65-63.71$ & 16.62 \\
\hline$\beta-\mathrm{HCH}$ & $0.28-21.10$ & 4.50 & $5.50-55.89$ & 23.54 & $6.27-382.44$ & 47.17 \\
\hline$\gamma-\mathrm{HCH}$ & $0.13-24.55$ & 3.85 & $6.13-120.96$ & 36.51 & $14.44-235.57$ & 70.70 \\
\hline$\delta-\mathrm{HCH}$ & $0.14-157.89$ & 14.32 & $15.43-140.08$ & 63.87 & $8.92-346.91$ & 118.07 \\
\hline heptachlor & $0.05-3.22$ & 0.89 & $1.31-12.00$ & 6.52 & $2.46-26.55$ & 10.22 \\
\hline aldrin & $0.11-2.00$ & 0.54 & $0.31-1.70$ & 0.83 & $0.09-1.93$ & 0.49 \\
\hline heptachlorepoxide(isomerA) & $0.03-2.51$ & 0.38 & $0.08-0.96$ & 0.33 & $0.03-0.43$ & 0.14 \\
\hline heptachlorepoxide(isomerB) & $0.10-10.95$ & 2.51 & $0.68-6.45$ & 2.41 & $0.11-4.20$ & 1.03 \\
\hline$o, p^{\prime}-D D E$ & $0.03-1.05$ & 0.37 & $0.06-0.96$ & 0.61 & $0.08-6.38$ & 0.56 \\
\hline tetrachlorvinphos & $0.12-11.44$ & 1.63 & $0.30-6.32$ & 2.90 & $0.35-8.93$ & 2.75 \\
\hline $\mathrm{p}, \mathrm{p}^{\prime}-\mathrm{DDE}$ & $0.03-2.17$ & 0.43 & $0.21-2.59$ & 0.87 & $0.03-4.22$ & 0.87 \\
\hline$o, p^{\prime}-D D D$ & $0.01-1.00$ & 0.15 & $0.01-1.02$ & 0.30 & $0.01-1.92$ & 0.22 \\
\hline endrin & $0.37-26.28$ & 4.74 & $1.06-10.63$ & 5.26 & $0.25-18.62$ & 4.53 \\
\hline $\mathrm{p}, \mathrm{p}^{\prime}-\mathrm{DDD}$ & $0.04-4.32$ & 0.98 & $0.28-3.73$ & 1.71 & $0.11-364.37$ & 25.25 \\
\hline$o, p^{\prime}-D D T$ & $0.04-115.53$ & 4.68 & $0.29-2.69$ & 1.27 & $0.07-18.92$ & 1.16 \\
\hline $\mathrm{p}, \mathrm{p}^{\prime}-\mathrm{DDT}$ & $0.10-4.50$ & 0.77 & $0.35-3.23$ & 1.51 & $0.15-3.83$ & 0.91 \\
\hline$\sum \mathrm{HCH}$ & $2.41-178.18$ & 19.85 & $51.76-241.23$ & 135.77 & $74.13-517.49$ & 262.19 \\
\hline$\sum \mathrm{DDT}$ & $0.94-116.83$ & 7.37 & $2.82-12.23$ & 6.27 & $1.20-370.98$ & 28.97 \\
\hline Eother OCP & $3.64-37.17$ & 16.23 & $11.35-37.67$ & 23.66 & 7.94-110.13 & 36.59 \\
\hline$\sum \mathrm{OCPs}$ & $9.35-194.93$ & 43.45 & $77.85-281.38$ & 165.70 & $88.57-900.10$ & 328.11 \\
\hline$\alpha-\mathrm{HCH} / \gamma-\mathrm{HCH}$ & $0.02-6.01$ & 0.92 & $0.03-2.77$ & 0.52 & $0.02-29.23$ & 1.32 \\
\hline$(\mathrm{DDE}+\mathrm{DDD}) / \Sigma \mathrm{DDT}$ & $0.01-0.79$ & 0.54 & $0.35-0.85$ & 0.56 & 0.29-0.99 & 0.66 \\
\hline
\end{tabular}

(178.18 ng/L) and DDT (116.83 ng/L) were much lower than the guideline values.

\section{Concentrations of OCPs in Suspended Solids}

The Weihe is not only a large river, but also has complexity in its bottom environment so that the content

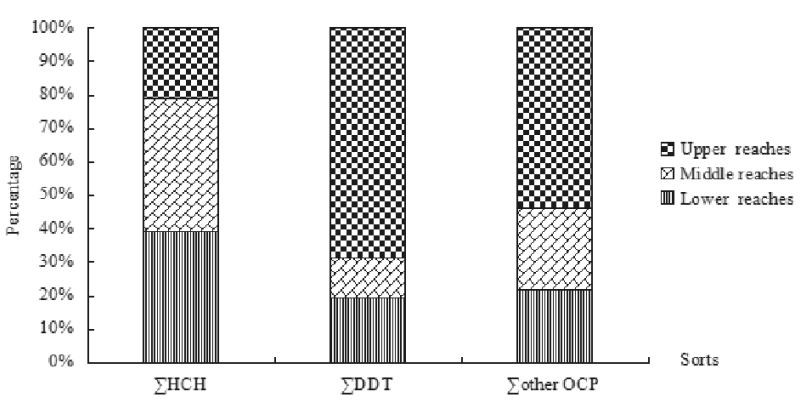

Fig. 2 Percentage composition of OCPs in surface water

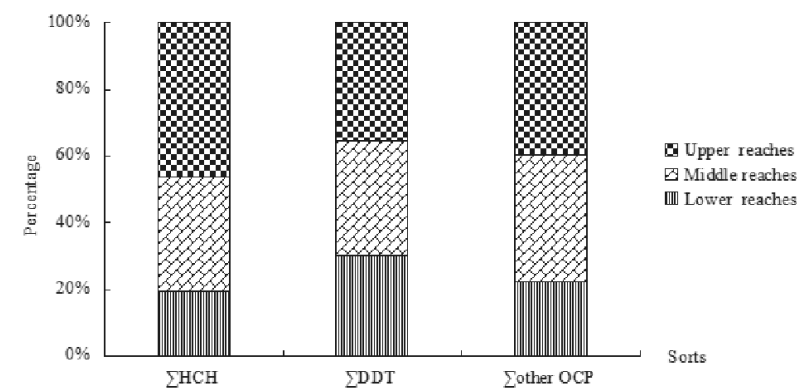

Fig. 3 Percentage composition of OCPs in suspended soilds. 
Table. 2. Concentrations of HCHs and DDT in water and sediments of lakes and rivers around the world.

\begin{tabular}{|c|c|c|c|c|}
\hline \multirow{5}{*}{ Later (ng/L) } & LHCH & LDDT & Reference \\
\hline & Weihe River, China & $2.41-178.18$ & $0.94-116.83$ & This study \\
\cline { 2 - 5 } & Chenab River, Pakistan & $0.10-6.50$ & $2.92-15.22$ & $2014[16]$ \\
\cline { 2 - 5 } & Baiyangdian Lake, China & $3.13-10.60$ & $4.05-20.59$ & $2011[11]$ \\
\cline { 2 - 5 } & Yangtze River, China & $0.55-28.07$ & - & $2008[17]$ \\
\cline { 2 - 5 } & Qiantang River, China & $0.74-202.8$ & $0.40-97.54$ & $2006[14]$ \\
\cline { 2 - 5 } & Küçük Menderes River, Turkey & $101-398$ & nd-120 & $2003[15]$ \\
\hline \multirow{5}{*}{ Sediment (ng/g dw) } & Nestos River, Greek & nd-68 & nd-64 & $2003[18]$ \\
\cline { 2 - 5 } & Weihe River, China & $74.13-517.49$ & $1.20-370.98$ & This study \\
\cline { 2 - 5 } & Ravi River, Pakistan & nd-16 & $1.5-58.5$ & $2014[20]$ \\
\cline { 2 - 5 } & Lake Qarun, Egypt & $0.13-62.6$ & nd-5.88 & $2013[9]$ \\
\cline { 2 - 5 } & Baiyangdian Lake, China & $1.75-5.70$ & $0.91-6.48$ & $2011[11]$ \\
\cline { 2 - 5 } & Hanoi area, Vietnam & $<0.2-36$ & $4.4-1100$ & $2010[22]$ \\
\hline
\end{tabular}

${ }^{\mathrm{a}}$ nd: not detected

of suspended solids will also have great differences. In suspended solid samples, OCP concentrations ranged from 77.85 to $281.38 \mathrm{ng} / \mathrm{L}$ with a mean value of $165.70 \mathrm{ng} / \mathrm{L}$ (Table 1). These concentrations were obviously higher than in water $(9.35-194.93 \mathrm{ng} / \mathrm{L})$, perhaps because Weihe flow speed is too fast around these sites during sampling, resulting in sediment resuspension, and contaminants may be released from sediments into the suspended solids. This seems to be a local source of OCPs for these sites, which need to be further studied. The concentrations of HCHs and DDT ranged from 51.76 to $241.23 \mathrm{ng} / \mathrm{L}$ (mean value of $135.77 \mathrm{ng} / \mathrm{L}$ ), and 2.82 to $12.23 \mathrm{ng} / \mathrm{L}$ (mean value of $6.27 \mathrm{ng} / \mathrm{L}$ ), respectively (Table 1 ). The concentrations of HCHs and DDT are similar at the upper reaches, middle reaches, and lower reaches of the Weihe (Fig. 3).

\section{Concentrations of OCPs in Sediments}

$\mathrm{HCH}$ and DDT were detected in all sediment samples, with total concentrations ranging from 74.13

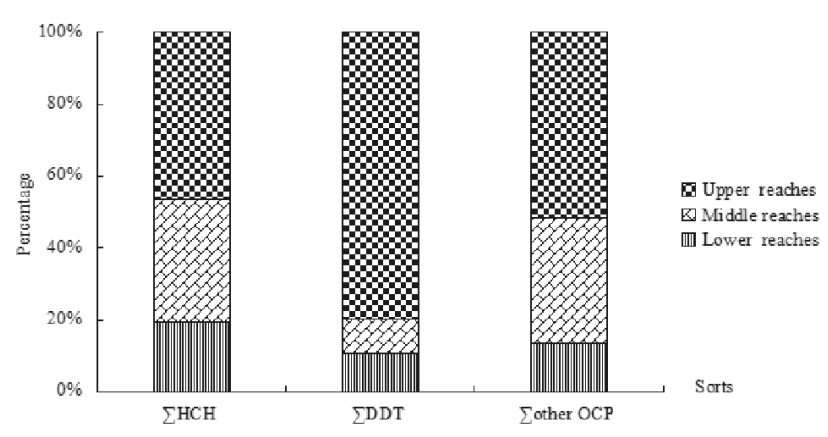

Fig. 4 Percentage composition of OCPs in sediments. to $517.49 \mathrm{ng} / \mathrm{g}$, and 1.20 to $370.98 \mathrm{ng} / \mathrm{g}$, respectively (Table 1). For HCHs, the mean concentrations of the $\mathrm{HCH}$ isomers in sediments decreased in the following order: $\delta$-HCH $(118.07 \mathrm{ng} / \mathrm{g})>\gamma-\mathrm{HCH}(70.70 \mathrm{ng} / \mathrm{g})>\beta-\mathrm{HCH}$ $(47.17 \mathrm{ng} / \mathrm{g})>\alpha-\mathrm{HCH}(26.25 \mathrm{ng} / \mathrm{g})$. The DDD (p,p'-DDD, o,p'-DDD) occupied $88 \%$ of total DDT in sediments. The DDT level was higher than that of HCHs at the upper reaches of the Weihe (Fig. 4), in accordance with previous studies on OCP residues in sediments in China. This may be because DDT has low-water solubility, vapor pressure, biodegradability, high lipophilicity, and particle affinity compared with HCHs $[9,12]$.

In comparison, the levels of HCHs in Weihe sediments were much higher than those observed in Ravi River sediments in Pakistan [20], and the Gomti River in India [21]. The DDT levels in Weihe sediments were much lower than those in the Hanoi area of Vietnam [22] (Table $2[20-22])$.

\section{Ratios of $\alpha-\mathrm{HCH} / \gamma-\mathrm{HCH}$ in Environments}

Composition differences of $\mathrm{HCH}$ isomers or DDT congeners in the environment could reveal different pollution sources. Typical technical $\mathrm{HCH}$ contains $\alpha-\mathrm{HCH}$ $(60-70 \%), \quad \beta-\mathrm{HCH} \quad(5-12 \%), \quad \gamma-\mathrm{HCH} \quad(10-15 \%)$, and $\delta$ - $\mathrm{HCH}(610 \%), \gamma-\mathrm{HCH}$ is above $99 \%$ in lindane. It should be noted that $\alpha-\mathrm{HCH}$ and $\gamma-\mathrm{HCH}$ could be converted to $\beta-\mathrm{HCH}$ in the environment. Therefore, $\beta-\mathrm{HCH}$ was the most stable isomer of $\mathrm{HCHs}$ because of its lower vapor pressure. The abundance of $\beta-\mathrm{HCH}$ as the only isomer indicated that most $\mathrm{HCHs}$ came from older residues in the study area [23]. The possible sources of HCHs in the environment are historical residues or recent inputs of 


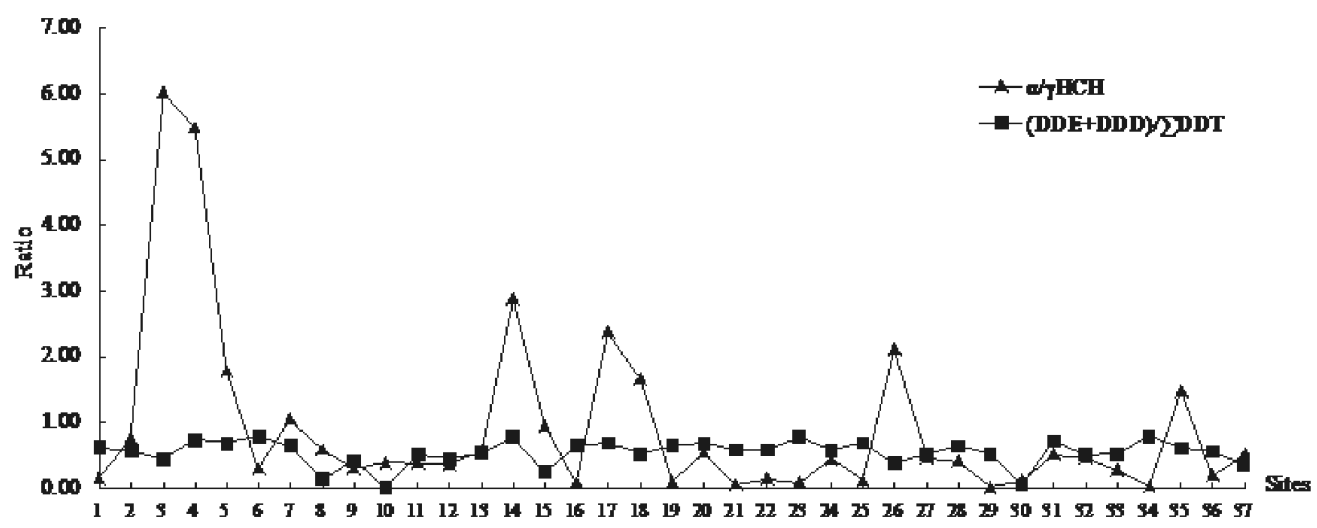

Fig. 5 Relationship between $\alpha / \beta \mathrm{HCH}$ and (DDE+DDD)/ $/ \sum D D T$ in surface water.

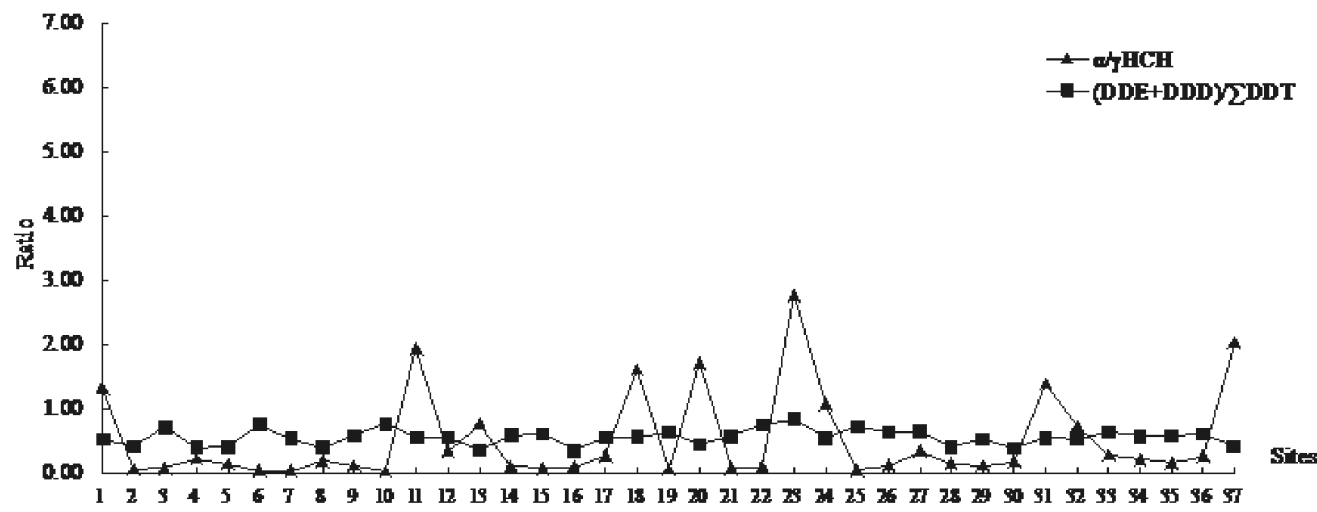

Fig. 6. Relationship between $\alpha / \beta \mathrm{HCH}$ and (DDE+DDD)/ $/ \mathrm{DDT}$ in suspended soilds.

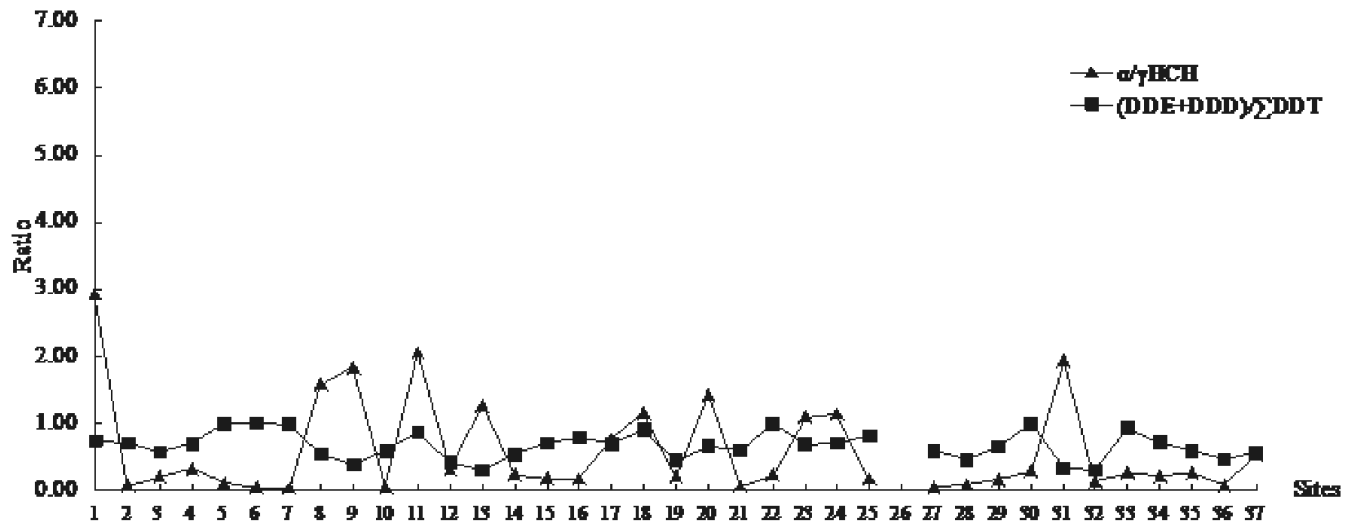

Fig. 7. Relationship between $\alpha / \beta \mathrm{HCH}$ and (DDE+DDD)/ $/ \mathrm{DDT}$ in sediments.

Table 3. Assessments of ecological risks of selected OCPs in Weihe River surface sediments.

\begin{tabular}{|c|c|c|c|c|c|c|}
\hline Chemical & Range $(\mathrm{ng} / \mathrm{g})$ & ERL $^{\mathrm{a}}$ & ERM $^{\mathrm{b}}$ & ${\text { <ERL }(\%)^{\mathrm{c}}}$ & ${\text { ERL-ERM }(\%)^{\mathrm{c}}}$ & $>_{\mathrm{ERM}(\%)^{\mathrm{c}}}$ \\
\hline o,p'-DDT and p,p'-DDT & $0.34-22.60$ & 1 & 7 & 44 & 53 & 3 \\
\hline o,p'-DDE and p,p'-DDE & $0.17-8.81$ & 2.2 & 27 & 78 & 22 & 0 \\
\hline o,p'-DDD and p,p'-DDD & $0.13-364.66$ & 2 & 20 & 64 & 23 & 13 \\
\hline DDTs & $1.20-370.98$ & 1.58 & 46.1 & 8 & 81 & 11 \\
\hline
\end{tabular}

${ }^{a}$ Effects range-low value $\quad{ }^{b}$ Effects range-median value ${ }^{c}$ Percentage of samples above the corresponding levels 
industrial $\mathrm{HCHs}$ or lindane, which can be identified by their isomer ratios such as $\alpha-\mathrm{HCH} / \gamma-\mathrm{HCH}$. In this study, $\delta-\mathrm{HCH}$ was the predominant isomer and was detected in all water, suspended solids, and sediment samples, while $\alpha, \beta, \gamma-\mathrm{HCH}$ were lower, with $\alpha / \gamma-\mathrm{HCH}$ ratios ranging from 0.02 to 6.01 (mean value of 0.92 ) for water, and 0.03 to 2.77 (mean value of 0.52 ) for suspended solids, and 0.02 to 29.23 (mean value of 1.32) for sediments. The $\alpha-\mathrm{HCH} / \gamma-\mathrm{HCH}$ ratio in areas where lindane has been used typically range between 0.2 and 1 , due to the photochemical transformation of $\gamma-\mathrm{HCH}$ to $\alpha-\mathrm{HCH}$, compared to a range of 4-15 for technical mixtures of $\mathrm{HCH}$ [24]. The high $\alpha-\mathrm{HCH} / \gamma-\mathrm{HCH}$ ratio in sites 3 and 4 range between 5 and 6 in Fig. 5, which indicated that historical usage of technical mixtures of $\mathrm{HCHs}$ was the main source of $\mathrm{HCH}$ in the water.

\section{Ratios of (DDE+DDD)/ $2 \mathrm{DDT}$ in Environments}

The relative concentration of DDT and its metabolites can provide useful information on pollution sources. Technical DDT generally contains p, $\mathrm{p}^{\prime}$-DDT (75\%), o, $\mathrm{p}^{\prime}-$ DDT $(15 \%)$, and p, $\mathrm{p}^{\prime}-\mathrm{DDE}(5 \%)$, and less o, $\mathrm{p}^{\prime}-\mathrm{DDE}$, $\mathrm{p}, \mathrm{p}^{\prime}$-DDD, and o, $\mathrm{p}^{\prime}$-DDD. Generally speaking, a ratio of (DDE+DDD)/ $\Sigma$ DDT of more than 0.5 indicates longterm biotransformation of DDT to DDE and DDD, while a ratio of less than 0.5 may indicate recent input of DDT [25]. Dicofol was probably the new input source, an acaricide manufactured from technical DDT used mainly in orchards to treat mites in Shaanxi Province on a small scale. The ratios of (DDE+DDD)/ $\Sigma$ DDT found in the Weihe ranged from 0.01 to 0.79 (mean value of 0.54 ) for water, 0.35 to 0.85 (mean value of 0.56 ) for suspended solids, and 0.29 to 0.99 (mean value of 0.66 ) for sediments (Table 1), with most values being more than 0.5 (Figs 5-7). This indicated that the DDT compounds in the Weihe may be mainly derived from DDT-treated aged and weathered agricultural sources (note that site 26 did not collect samples in sediments).

\section{Ecological Risk Assessment}

It is necessary to maintain aquatic ecosystems of long-term stability and therefore do risk assessments in sediments. Because there is no way to evaluate the ecological risk by $\mathrm{HCH}$, we evaluated DDT. The effects range-low value (ERL) and effects range-median value (ERM) guidelines [26] were applied to evaluate the possible ecological risk assessment of OCP contamination in the Weihe (Table 3). When pollutant content in sediments is less than ERL, ecological risk is less than $10 \%$; when the pollutant content in sediments is greater than ERM, ecological risk is greater than $75 \%$ [27]. The value of DDE (o,p'-DDE and p,p'-DDE) in sediment samples is less than ERM, and the value of DDE in $78 \%$ of the samples was less than ERL. On the whole, Weihe sediments have a high ecological risk from pesticides.

\section{Conclusions}

In the present study we provided the first systemic data on OCP levels in surface water, suspended solids and sediments from the Weihe River in northwest China. Results showed that OCPs in surface water, suspended solids, and sediments were in the range of 9.35-194.93 ng/L, $77.85-281.38 \mathrm{ng} / \mathrm{L}$, and 88.57-900.10 ng/g, respectively. $\mathrm{HCHs}$ and DDT were the dominating components of OCPs in water, suspended solids, and sediment samples. The concentrations of $\mathrm{HCHs}$ and DDT in Weihe water were all below the threshold prescribed by official Chinese guidelines (GB3838-2002), thus it is within the acceptable level. The $\alpha-\mathrm{HCH} / \gamma-\mathrm{HCH}$ ratio indicated that historical usage of technical mixtures of HCHs was the main source of $\mathrm{HCH}$ in the Weihe. Meanwhile, new input of $\gamma-\mathrm{HCH}$ existed in this region, indicating the recent application of prohibited pesticides such as linane, which emphasizes the importance of pesticide control in this region. The DDT ratio indicated that the DDT found at most sites came from past uses of technical DDT in the river. Compared with some guideline values for DDT in sediments, the DDT concentrations have high ecological risk. Thus, more research is needed in the future to address this contamination.

\section{Acknowledgements}

Our research was supported by the National Natural Science Foundation of China (Nos. 41072185, 41372259, and 41302206), and the Natural Science Foundation of Shaanxi Province, China (No. 2014JM5204).

\section{References}

1. ZHANG G., PARKER A., HOUSE A., MAI B.X., LI X.D., KANG Y.H., WANG Z.S. Sedimentary records of DDT and $\mathrm{HCH}$ in the Pearl River Delta, South China. Environ Sci Technol, 36 (17), 3671, 2002.

2. WAN Y., HU J.Y., LIU J.L., AN W., TAO S., JIA Z.B. Fate of DDT-related compounds in Bohai Bay and its adjacent Haihe Basin, North China. Mar Pollut Bull, 50 (4), 439, 2005.

3. TAO S., XU F.L., WANG X.J., LIU W.X., GONG Z.M., FANG J.Y., ZHU L.Z., LUO Y.M. Organochlorine pesticides in agricultural soil and vegetables from Tianjin, China. Environ Sci Technol, 39 (8), 2494, 2005.

4. LI Y.F., CAI D.J., SHAN Z.J., ZHU Z.L. Gridded usage inventories of technical hexachlorocyclohexane and lindane for China with $1 / 6$ latitude by $1 / 4$ longitude resolution. Arch Environ Contam Toxicol, 41 (3), 261, 2001.

5. YANG X., WANG S., BIAN Y., CHEN F., YU G., GU C., JIANG X. Dicofol application resulted in high DDTs residue in cotton fields from northern Jiangsu province, China. J Hazard Mater, 150 (1), 92, 2008.

6. CRISP T.M., CLEGG E.D., COOPER R.L., WOOD W.P., ANDERSEN D.G., BAETCKE K.P., HOFFMANN J.L., MORROW M.S., RODIER D.J., SCHAEFFER J.E., TOUART L.W., ZEEMAN M.G., PATEL Y.M. Environmental endocrine disruption: an effects assessment 
and analysis. Environ Health Perspect, 106 (1), 11, 1998.

7. YANG H., BATTARBEE R.W., TURNER S.D., ROSE N.L., DERWENT R.G., Wu G., YANG R., Historical reconstruction of mercury pollution across the Tibetan plateau using lake sediments. Environ. Sci. Technol, 44 (8), 2918, 2010.

8. QIU Y.W., ZHANG G., GUO L.L., CHENG H.R., WANG W.X., LI X.D., WAI O.W.H.Current status and historical trends of organochlorine pesticides in the ecosystem of Deep Bay, South China. Estuarine Coastal Shelf Sci. 85 (2), 265, 2009.

9. BARAKAT A.O., KHAIRY M., AUKAILY I. Persistent organochlorine pesticide and $\mathrm{PCB}$ residues in surface sediments of Lake Qarun, a protected area of Egypt. Chemosphere, 90 (9), 2467, 2013.

10. DOONG R.A., LEE S.H., LEE C.C., SUN Y.C., WU S.C. Characterization and composition of heavy metals and persistent organic pollutants in water and estuarinesediments from Gaoping River, Taiwan. Mar Pollut Bull, 57 (6-12), 846, 2008.

11. DAI G.H., LIU X.H., LIANG G., HAN X., SHI L., CHENG D.M., GONG W.W. Distribution of organochlorine pesticides $(\mathrm{OCPs})$ and polychlorinated biphenyls (PCBs) in surface water and sediments from Baiyangdian Lake in North China. J Environ Sci, 23 (10), 1640, 2011.

12. YANG R.Q., LV A.H., SHI J.B., JIANG G.B. The levels and distribution of organochlorine pesticides (OCPs) in sediments from the Haihe River, China, Chemosphere, 61 (3), 347, 2005.

13. ZHAO Z.H., ZHANG L., WU J.L., FAN C.X., SHANG J.G. Assessment of the potentialmutagenicity of organochlorine pesticides (OCPs) in contaminated sedimentsfrom Taihu Lake, China. Mutat Res, 696 (1), 62, 2010.

14. ZHOU R.B., ZHU L.Z., YANG K., CHEN Y.Y. Distribution of organochlorine pesticides in surface water and sediments from Qiantang River, East China. J Hazard Mater, 137 (1), 68, 2006.

15. TURGUT C. The contamination with organochlorine pesticides and heavy metals in surface water in Kucuk Menderes River in Turkey, 2000-2002. Environ Int, 29 (1), 29, 2003.

16. MAHMOOD A., MALIK R.N., LI J., ZHANG G. Levels, distribution pattern and ecological risk assessment of organochlorines pesticides (OCPs) in water and sediments from two tributaries of the Chenab River, Pakistan Ecotoxicology, 23, 1713, 2014.

17. TANG Z.W., YANG Z.F., SHEN Z.Y., NIU J.F., CAI Y.P. Residues of organochlorines pesticides in water and suspended particulate matter from the Yangtze River catchment of Wuhan, China. Environ Monit Assess, 137, 427, 2008.

18. GOLFINOPOULOS S.K., NIKOLAOU A.D., KOSTOPOULOU M.N., XILOURGIDIS N.K., VAGI M.C., LEKKAS D.T. Organochlorine pesticides in the surface waters of Northern Greece. Chemosphere, 50 (4), 507, 2003.

19. GB 3838-2002. Environmental quality standards for surface water, China, 2002.

20. SYED J.H., MALIK R.N., LI J., CHAEMFA C., ZHANG G., JONES K.C. Status, distribution and ecological risk of organochlorines (OCs) in the surface sediments from the Ravi River, Pakistan. Sci Total Environ, 472, 204, 2014.

21. MALIK, A., OJHA, P., SINGH, K.P. Levels and distribution of persistent organochlorine pesticide residues in water and sediments of Gomti River (India) - a tributary of the Ganges River. Environ Monit Assess, 148, 421, 2009.

22. HOAI P.M., NGOC N.T., MINH N.H., VIET P.H., BERG M., ALDER A.C., GIGER W. Recent levels of organochlorine pesticides and polychlorinated biphenyls in sediments of the sewer system in Hanoi, Vietnam. Environ Pollut, 158 (3), 913, 2010.

23. DOONG R.A., SUN Y.C., LIAO P.L., PENG C.K., WU S.C. Distribution and fate of organochlorine pesticide residues in sediments from the selected rivers in Taiwan. Chemosphere, 48 (2), 237, 2002.

24. MCCONNELL L.L., COTHAM W.E., BIDLEMAN T.F. Gas exchange of hexachlorocyclohexane in the Great Lakes. Environ Sci and Technol, 27 (7), 1304, 1993.

25. HITCH R.K., DAY H.R. Unusual persistence of DDT in some western USA soils. Bull Environ Contam Toxicol, 48 (2), 259, 1992.

26. LONG E.R., MACDONALD D.D., SMITH S.L., CALDER F.D. Incidence of adverse biological effects within ranges of chemical concentrations in marine and estuarine sediments. Environmental Management, 19, 81, 1995.

27. LI F., QI SHI.H., LIU J., HU Y., QU CH.K., LIU H.X. Distribution and Risk Assessment of Organochlorine Pesticides in Surface Sediment from Birds Gathering Area in Honghu Lake. Environ Sci Technol, 37 (1), 183, 2014. 